\title{
Correlation of HPV-16/18 infection of human papillomavirus with lung squamous cell carcinomas in Western China
}

\author{
YAN YU, AIMIN YANG, SENKE HU and HONG YAN \\ Department of Public Health, Xi'an Jiaotong University School of Medicine, \\ No. 76, West Yanta Road, Xi'an, Shaanxi 710061, P.R. China
}

Received January 16, 2009; Accepted March 31, 2009

DOI: 10.3892/or_00000397

\begin{abstract}
Prevalent inconsistency of human papillomavirus (HPV) infection in lung cancer was found among recent studies from different countries with racial and geographic variations. Even in Chinese populations, the prevalent discrepancy of HPV infection in lung cancer patients was also found with the geographic variations and tumor types. To study the difference of HPV-16/18 infection in lung squamous cell carcinomas and non-cancer controls, we conducted this study to verify whether there was a similar HPV infection prevalence pattern in lung squamous cell carcinoma patients from the Western part of China. Paraffinembedded samples (180), of 72 lung squamous cell carcinomas, 37 lung adenocarcinomas and 71 non-cancer controls, were analyzed by INNO-LIPA Genotype polymerase chain reaction (PCR) and real-time PCR analysis. The data showed that $51.4 \%(37 / 72)$ of lung squamous cell carcinoma samples, $16.2 \%(6 / 37)$ of adenocarcinoma, and $22.5 \%$ (16/71) of non-cancer controls were HPV DNA positive. The risk of lung squamous cell carcinomas was 3.5 times higher among people HPV-positive (odds ratio 3.5, 95\% CI 1.6-7.3, $\mathrm{p}<0.001)$ compared with the HPV- negative population. Adjusted by smoking status, the risk of lung squamous cell carcinomas was 3.5 times higher among people HPVpositive (odds ratio 3.5, 95\% CI 1.7-7.5, p=0.001) compared with the HPV-negative population. The risk of lung squamous cell carcinomas was 16.9 times higher for patients with positive HPV-16 (odds ratio 16.9, 95\% CI 3.8-75.3, $\mathrm{p}<0.0001)$ than negative HPV-16. Adjusted by smoking status, the risk of lung squamous cell carcinomas was 17.4 times higher among people HPV-16 positive (odds ratio 17.4, 95\% CI 3.9-77.5, p<0.0001) compared with HPV-16 negative people. INNO-LIPA Genotype analysis revealed that the frequency of high risk HPV-16 and 18 genotype in
\end{abstract}

Correspondence to: Dr Hong Yan, Department of Public Health, Xi'an Jiaotong University School of Medicine, No. 76, West Yanta Road, Xi'an, Shaanxi 710061, P.R. China

E-mail: hongyanpaper2008@yahoo.com

Key words: human papillomavirus, viral load, integration, lung squamous cell carcinoma, the west part of China lung squamous cell carcinoma cases appeared to be significant higher than that in the non-cancer controls $(\mathrm{P}<0.001)$, and the most frequent genotype was HPV-16 (21 cases), followed by HPV-18 (6 cases), HPV-16/18 (4 cases) in lung squamous cell carcinomas, respectively, and the majority genotype was HPV-6 (9 cases) in controls. The HPV-16 $\mathrm{E}_{2} / \mathrm{E}_{6}$ ratio was significantly lower than the unity, suggested that the main presence of integrated form of HPV16 genome (16/27) may contribute more to lung squamous cell carcinomas, despite its viral load estimated to be only $<1$ to 2 copies per cell.

\section{Introduction}

Human papillomavirus (HPV) is a double stranded DNA virus, and is an established etiological agent causing cervix cancer. Its high-risk genotypes, including HPV-16 and -18, are associated with cervix cancer and other genital cancers $(1,2)$. Lung cancer is a major health problem and the leading cause of cancer deaths in the world. The pathogenesis of lung cancer is complex, and is believed to be due to the interaction between environmental and genetic factors. Various evidence shows that HPV might be associated with bronchial carcinogenesis and lung cancer (3-6).

Although smoking was the most frequent risk factor of lung cancer, the mechanism is not clear (7). Etiological involvement of HPV in development of lung cancer was originally postulated (8-10). Inconsistency in prevalence of human papillomavirus (HPV) infection in lung cancer was found among recent studies from different countries with racial and geographic variations. A large sample investigation reported that HPV DNA infection rate was $21.7 \%$ in 2468 lung carcinomas (11). HPV infection is considered a cocarcinogen of lung cancer and its contribution to pathogenesis has been evaluated (12-18). However, even in Asian populations, the prevalence discrepancy of HPV infection in lung cancer patients was also found with the geographic variations and tumor types. A study in Taiwan (13) reported that $77(54.6 \%)$ of 141 lung tumors had HPV-16 or -18 DNA compared with 16 (26.7\%) of 60 non-cancer control subjects among non-smoking Taiwanese women, and a recent study from mainland China suggested that the rates of HPV-16 and/or -18 infections in patients with 73 lung tumors were significantly higher than in 34 non-cancer control subjects (27.7 vs. $5.9 \%$ ) (19). In the central part of China 
investigators have found that $44.1 \%$ of (138/313) NSCLC samples are positive, while $4.2 \%$ (4/96) of lung benign controls are positive (20).

To study the role of integration of HPV-16 DNA into the host genome which may contribute to lung squamous cell carcinoma development, we conducted this study to verify whether there was a similar HPV infection prevalence pattern and HPV-16 integration status in lung squamous cell carcinoma patients from Western China.

\section{Materials and methods}

Samples. The 180 paraffin-embedded samples, of 72 lung squamous cell carcinomas, 37 lung adenocarcinomas and 71 non-cancer controls were collected and diagnosed in the first affiliated hospital of Xi'an Jiaotong University, China. The 71 non-cancer controls included tuberculomas 41, hypertrophy 19, granuloma 8, and pseudoplasm 3, respectively. All of these cases were from the West part of China during the period from 2005 to December 2007. The demographic features review and statistical analysis were approved by the Department of Public Health, Xi'an Jiaotong University School of Medine, China. The study was approved by the Ethics Committee of Xi'an Jiaotong University, China.

DNA extraction. Formalin-fixed paraffin-embedded samples were cut into $10 \mu \mathrm{m}$ slices and prepared according to the method described before (21). The specimens were treated with $1 \mathrm{ml}$ of xylene, and then with $1 \mathrm{ml}$ of ethanol. After centrifugation, the pellet was resuspended in digestion buffer (50 mM Tris-Cl pH 8.0, 1 mM EDTA pH 8.0,0.5\% Tween-20) containing $200 \mu \mathrm{g}$ of proteinase $\mathrm{K}$ (Invitrogen) and incubated at $56^{\circ} \mathrm{C}$ overnight. After the incubation, the solution was heated at $100^{\circ} \mathrm{C}$ for $10 \mathrm{~min}$ and centrifuged. An aliquot of the supernatant was directly used for PCR.

$\beta$-globin PCR. $\beta$-globin amplification with $\mathrm{PCO}_{3} / \mathrm{PCO}_{4}$ $(110 \mathrm{bp})$ primers $\left(\mathrm{PCO}_{3}\right.$ primer 5'-ACACAACTGTGTTCA CTGC-3' and $\mathrm{PCO}_{4}$ primer 5'-CAACTTCATCCACGTTC ACC-3') was used as the internal positive control (22). PCR condition was as follows: the initial denaturation at $95^{\circ} \mathrm{C}$ for $4 \mathrm{~min}, 40$ cycles with the cycling profile of $95^{\circ} \mathrm{C}$ for $1 \mathrm{~min}$, $52^{\circ} \mathrm{C}$ for $1 \mathrm{~min}$ and $72^{\circ} \mathrm{C}$ for $2 \mathrm{~min}$ and the final extension for 5 min at $72^{\circ} \mathrm{C}$. DNA purified from HeLa cells containing, HPV-16 was used as external positive control.

INNO-LIPA genotyping system. A 65 bp region of L1 gene of the HPV genome was amplified by PCR using short PCR fragment (SPF10) biotinylated primers. The PCR products were visualized on $4 \%$ agarose gel with ethidium bromide staining by electrophoresis and $(10 \mu 1)$ of the PCR product was denaturized and hybdidized with specific oligonucleotide probes (25 HPV type-specific probes) immobilized as parallel lines on a nitrocellulose membrane strips, following the manufacturer's instructions (INNO-LIPA HPV genotyping kit, Inno-genetics, Belgium). The 28 probes for 25 different HPV genotypes in each INNO-LIPA strip are described elsewhere (23). The strips were interpreted with a labeled acetate overlay with lines indicating the position of each probe relative to the reference mark.
Real-time PCR. Real-time PCR was performed with the ABI Prism 7000 Sequence Detection System and SYBR-Green PCR master mix (PE, Applied Biosystems). The amplification conditions were 15 cycles at $95^{\circ} \mathrm{C}$ and a two-step cycle of $95^{\circ} \mathrm{C}$ for $30 \mathrm{sec}$ and $60^{\circ} \mathrm{C}$ for $60 \mathrm{sec}$ for a total of 40 cycles. The used primer sets were as follows: $\mathrm{E}_{6} \mathrm{~F}$ : GAGAAACTG CAATGTTTCAGGACC and $\mathrm{E}_{6} \mathrm{R}$ : TGTATAGTTGTTTGC AGCTCTGTGC; E $\mathrm{F}$ : AACGAAGTATCCTCTCCTGAA ATTATTAG, and $\mathrm{E}_{2} \mathrm{R}$ : CCAAGGCGACGGCTTTG. Those primers amplify a fragment of $\mathrm{E}_{6}(81 \mathrm{bp})$ and $\mathrm{E}_{2}(76 \mathrm{bp})$ ORFs, respectively (24). The final concentration of primers was $0.5 \mu \mathrm{M}$. All the experiments were made in duplicate. The specificity of amplification was confirmed using dissociation analysis starting at $60^{\circ} \mathrm{C}$ and agarose gel electrophoresis of amplified products.

Statistical analysis. The central focus of our analysis was to examine the independent associations between HPV infection and lung squamous cell carcinomas, modeled as categorical variable. Significant differences in demographic characteristics and smoking status across case and control were assessed using $\chi^{2}$ test or Fisher's exact test for the equality of proportions. The associations between HPV status, HPV-16 status and lung squamous cell carcinomas were assessed using logistic regression and were expressed as the odds ratio (OR) and its 95\% CI. We evaluated possible effect modification by smoking status by adding product terms to the regression models. Differences were considered significant at $\mathrm{P} \leq 0.05$. We used Stata version 9.2 (Stata /SE 9.2 StataCorp, College Station, TX) for all analyses.

\section{Results}

Demographic features of lung carcinoma cases and controls are summarized. Male patients accounted for $66.7 \%$ (48 patients) of the 72 lung squamous cell carcinomas cases, $64.9 \%$ (24 patients) in 37 lung adenocarcinomas and $63.4 \%$ (45 patients) in 71 non-cancer control cases. The mean age of the cases and controls was $63.6 \pm 11.7$ years and $63.3 \pm 12.4$, respectively (data not shown).

The B-globin gene was successfully amplified by PCR in all samples. The HPV-positive signal was not only detected in the agarose-gel electrophoresis but was confirmed by INNO-LIPA HPV genotyping analysis kit. Thirty-seven cases were detected in the lung squamous cell carcinoma group, 6 cases were detected in 37 lung adenocarcinomas, while 16 cases were detected in non-cancer control group. The frequency of HPV-positive cases (51.4\%) was higher in lung squamous cell carcinomas than in adenocarcinomas and non-cancer control group (16.2 and 22.5\%) $(\mathrm{P}<0.001)$ (Table I).

Statistical analyses revealed that HPV infection was not correlated with gender, age, tumor stage and grades, but the positive rate of HPV is $42.5 \%$ (48/113) and $15.8 \%$ (3/19) in the smoker and non-smoker, respectively, and the frequency of HPV-positive in the cases was significantly associated with smoking habit $(\mathrm{p}=0.034)$ (Table II).

The risk of lung squamous cell carcinomas was 3.5 times higher among people HPV-positive (odds ratio 3.5, 95\% CI 1.6-7.3, $\mathrm{p}<0.001)$ compared with HPV-negative people. 
Table I. Difference of HPV DNA positive between lung cancer and non-cancer control cases.

\begin{tabular}{lcccc}
\hline & HPV-positive & HPV-negative & Total & $\chi^{2}$ \\
\hline SQCs & 37 & 35 & 72 & \\
Adenocarcinomas & 6 & 31 & 37 & \\
Non-cancer control & 16 & 55 & 71 & \\
\hline Total & 59 & 121 & 180 & 19.304 \\
\hline
\end{tabular}

Table II. Clinicopathological parameter features of HPV DNA detection by PCR in lung squamous cell carcinomas and noncancer control group.

\begin{tabular}{|c|c|c|c|c|}
\hline & HPV-positive & HPV-negative & $\chi^{2}$ & $\mathrm{P}$ \\
\hline Case & & & 18.551 & $<0.001$ \\
\hline Lung squamous cell carcinomas & 37 & 35 & 0.410 & 0.814 \\
\hline I & 6 & 4 & & \\
\hline II & 18 & 17 & & \\
\hline III & 13 & 14 & & \\
\hline Non-cancer control & 16 & 55 & & 0.062 \\
\hline Tuberculosis & 5 & 36 & & \\
\hline Hypertrophy & 7 & 12 & & \\
\hline Granuloma & 3 & 5 & & \\
\hline Pseudoplasm & 1 & 2 & & \\
\hline Gender & & & 0.028 & 0.865 \\
\hline Male & 34 & 59 & & \\
\hline Female & 19 & 31 & & \\
\hline Ages (years) & & & 1.794 & 0.408 \\
\hline$<55$ & 18 & 26 & & \\
\hline $55-64$ & 25 & 38 & & \\
\hline$\geq 65$ & 10 & 26 & & \\
\hline Smoking & & & 6.787 & 0.034 \\
\hline Non & 3 & 16 & & \\
\hline Smoker & 48 & 65 & & \\
\hline Unknown & 2 & 9 & & \\
\hline Total & 53 & 90 & & \\
\hline
\end{tabular}

Adjusted by smoking status, the risk of lung squamous cell carcinomas was 3.5 times higher among people HPVpositive (odds ratio 3.5 , 95\% CI 1.7-7.5, $\mathrm{p}=0.001$ ) compared with HPV-negative people.

The risk of lung squamous cell carcinomas was 16.9 times higher for people with positive HPV-16 (odds ratio 16.9, 95\% CI 3.8-75.3, p<0.0001) than those with negative HPV-16. Adjusted by smoking status, the risk of lung squamous cell carcinomas was 17.4 times higher for people with positive HPV-16 (odds ratio 17.4, 95\% CI 3.9-77.5, p<0.0001) than that with negative HPV-16. There was no association between smoking status and lung squamous cell carcinomas (Table III).

Analysis of HPV genotypes revealed that the predominant genotype was HPV-16 (21 cases), followed by
HPV-18 (6 cases), HPV-16/18 (4 cases), HPV-6 (4 cases) and other genotype ( 2 cases) in lung squamous cell carcinomas cases, but the major genotype was HPV-6 (9 cases), followed by other genotype (3 cases), HPV-16 (2 cases), HPV-6/18 (1 cases) and HPV-18 (1 case) in noncancer control cases. The high risk HPV genotypes 16 and/or 18 were detected in $43.06 \%$ (31/72) and $5.63 \%$ (4/71) in lung SQC cases and non-cancer control cases, respectively $(\mathrm{P}<0.001)$ (Table IV).

Results of real-time PCR analysis are summarized in Table V. The quantity of HPV-16 DNA ranged from 0.003 to 44.942 copies per nanogram of genomic DNA. Results from repeated analyses showed a difference less than $5 \%$ in all the cases. $\mathrm{E}_{2} / \mathrm{E}_{6}$ ratio was determined by real-time PCR. In 
Table III. Difference of HPV-positive and HPV-16 positive in lung squamous cell carcinomas and non-cancer control group associated with smoking habit.

\begin{tabular}{lcccc}
\hline & \multicolumn{2}{c}{ Lung squamous cell carcinomas } & \multicolumn{2}{c}{ Non-cancer control } \\
\cline { 2 - 3 } & HPV-positive & HPV-negative & HPV-positive & HPV-negative \\
\cline { 2 - 5 } Non-smoker & 4 & 26 & 2 & 6 \\
Smoker & 31 & 33 & 13 & 43 \\
Total & 35 & HPV-16 negative & HPV-16 positive & HPV-16 negative \\
\hline & HPV-16 positive & 9 & 1 & 7 \\
Non-smoker & 2 & 35 & 1 & 55 \\
Smoker & 22 & 44 & 2 & 62 \\
Total & 24 & & 59 \\
\hline
\end{tabular}

Table IV. HPV DNA genotypes detected by INNO-LIPA genotyping analysis.

\begin{tabular}{llc}
\hline HPV genotypes & $\begin{array}{l}\text { Lung squamous } \\
\text { cell carcinomas }\end{array}$ & $\begin{array}{c}\text { Non-cancer } \\
\text { control }\end{array}$
\end{tabular}

\begin{tabular}{lrrrl}
\hline HPV-16 & 21 & 2 & \\
HPV-18 & 6 & 1 & \\
HPV-6 & 4 & 9 & \\
HPV-16/HPV-18 & 4 & 0 & \\
HPV-6/HPV-18 & 0 & 1 & \\
Other HPV & 2 & 3 & \\
Total & 37 & 16 & $<0.001$ \\
\hline
\end{tabular}

16 cases $(59.26 \%), \mathrm{E}_{2}$ DNA was not detected. In the rest of the cases, $\mathrm{E}_{2}$ DNA was detected but the $\mathrm{E}_{2} / \mathrm{E}_{6}$ ratio was less than the unity.

\section{Discussion}

The frequency of lung carcinomas with HPV genomic sequences showed a wide range variation, from none to almost $80 \%(11,25,26)$. A review by Syrjanen (11) showed that HPV was detected in 536 of 2468 (22\%) bronchial carcinomas. Meanwhile a study from Okinawa, Japan found positive HPV in $79 \%$ of lung squamous cell carcinomas (12).

In our study, HPV was detected not only using SPF10 primer PCR, but was confirmed by INNO-LIPA HPV genotyping analysis. Thirty-seven cases were detected in the 72 lung squamous cell carcinoma group, 6 cases were detected in 37 lung adenocarcinomas, while 16 cases were detected in 71 non-cancer controls. The frequency of HPVpositive cases $(51.4 \%)$ was higher in lung squamous cell carcinomas than in non-cancer control group $(22.5 \%)$. The positive rate of HPV is $42.5 \%$ (48/113) and $15.8 \%$ (3/19) in the smoker and non-smoker, respectively. It seemed that the frequency of HPV-positivity is significantly associated to smoking habit $(\mathrm{P}=0.034)$, and HPV detection rate was not associated with gender or age. This percentage was higher than the value of $22 \%$ reported by Syrjanen in bronchial carcinomas (11), and lower than $79 \%$ reported from Okinawa of Japan in lung squamous cell carcinomas (12).
Lung squamous cell carcinoma development was strongly associated to smoking habit because more than $90 \%$ of individuals undergoing squamous cell carcinomas were heavy smokers (27). To find the correlation between the smoking status and the risk of lung squamous cell carcinomas in HPVpositive cases, the associations between HPV status, HPV-16 status and lung squamous cell carcinomas were assessed using a logistic regression model. We evaluated the possible effect modification by smoking status by adding product terms to the regression models.

We found that the risk of lung squamous cell carcinomas was 3.5 times higher among people HPV-positive (odds ratio 3.5, 95\% CI 1.6-7.3, p<0.001) compared with HPV- negative people. Adjusted by smoking status, the risk of lung squamous cell carcinomas was 3.5 times higher among people HPV-positive (odds ratio 3.5, 95\% CI 1.7-7.5, $\mathrm{p}=0.001$ ) compared with HPV-negative people. The risk of lung squamous cell carcinomas was 16.9 times higher among people HPV-16 positive (odds ratio 16.9, 95\% CI 3.8$75.3, \mathrm{p}<0.0001)$ compared with HPV-16 negative people. Adjusted by smoking status, the risk of lung squamous cell carcinomas was 17.4 times higher among people HPV-16 positive (odds ratio $17.4,95 \%$ CI 3.9-77.5, p<0.0001) compared with HPV-16 negative people. Interestingly, there was no association between smoking status and lung squamous cell carcinomas, while HPV-16 positive had a predominantly higher risk than HPV-16 negative for the development of lung squamous cell carcinomas in Western China.

Cheng et al reported that lung carcinomas with high risk HPV was much more frequently found among females than males $(4,13)$. The study from Japan (17) also reported that HPV-16 was more frequently found among female than male cases, and the frequency of HPV-16 positive cases among all the HPV-positive cases differed among the sexes. But in our study, no difference was found in gender and age. It was similar to the report from Noutsou et al (28) that no correlation was found between HPV infection with sex, age and clinical outcome of the patient, or the histological type and the differentiation grade of the tumor.

Meanwhile, some reports revealed that the higher risk of HPV-16 and HPV-18 were more strongly associated with non-small cell lung cancer $(14,15,29)$. But inconsistent 
Table V. HPV genotypes by INNO LIPA and HPV-16 viral loaded by RT-PCR.

\begin{tabular}{|c|c|c|c|c|c|c|}
\hline Sample & Group & Genotype & $\mathrm{E}_{2}$ copies/ng & $\mathrm{E}_{6}$ copies/ng & $\mathrm{E}_{2} / \mathrm{E}_{6}$ & Status \\
\hline 1 & SQCs & 16 & 0 & 0.087 & 0 & Integrated \\
\hline 2 & SQCs & 16 & 0 & 0.089 & 0 & Integrated \\
\hline 3 & SQCs & 16 & 0 & 0.003 & 0 & Integrated \\
\hline 4 & SQCs & 16 & 0 & 0.004 & 0 & Integrated \\
\hline 5 & SQCs & 16 & 0 & 0.014 & 0 & Integrated \\
\hline 6 & SQCs & 16 & 0 & 0.084 & 0 & Integrated \\
\hline 7 & SQCs & 16 & 0 & 0.013 & 0 & Integrated \\
\hline 8 & SQCs & 16 & 0.651 & 1.165 & 0.559 & Mix \\
\hline 9 & SQCs & 16 & 0.210 & 1.972 & 0.107 & Mix \\
\hline 10 & SQCs & 16 & 0 & 0.036 & 0 & Integrated \\
\hline 11 & SQCs & $16 / 18$ & 0.140 & 14.320 & 0.010 & Mix \\
\hline 12 & SQCs & 16 & 0 & 0.013 & 0 & Integrated \\
\hline 13 & SQCs & 16 & 0 & 0.005 & 0 & Integrated \\
\hline 14 & SQCs & $16 / 18$ & 0.005 & 1.223 & 0.004 & Mix \\
\hline 15 & SQCs & 16 & 1.866 & 14.123 & 0.132 & Mix \\
\hline 16 & SQCs & 16 & 0.074 & 1.035 & 0.071 & Mix \\
\hline 17 & SQCs & 16 & 0 & 0.004 & 0 & Integrated \\
\hline 18 & SQCs & 16 & 12.126 & 44.9422 & 0.270 & Mix \\
\hline 19 & SQCs & 16 & 0 & 0.011 & 0 & Integrated \\
\hline 20 & SQCs & $16 / 18$ & 0.371 & 5.242 & 0.071 & Mix \\
\hline 21 & SQCs & 16 & 0 & 0.003 & 0 & Integrated \\
\hline 22 & SQCs & 16 & 1.613 & 7.210 & 0.224 & Mix \\
\hline 23 & SQCs & 16 & 0 & 0.033 & 0 & Integrated \\
\hline 24 & SQCs & 16 & 0 & 0.051 & 0 & Integrated \\
\hline 25 & SQCs & $16 / 18$ & 0.480 & 10.928 & 0.044 & Mix \\
\hline 26 & control & 16 & 0 & 0.224 & 0 & Integrated \\
\hline 27 & control & 16 & 0.003 & 0.0326 & 0.089 & Mix \\
\hline
\end{tabular}

results were found among these studies. A study in Taiwan (13) reported that 77 (54.6\%) of 141 lung tumors had HPV-16 or -18 DNA compared with $16(26.7 \%)$ of 60 non-cancer control subjects among non-smoking Taiwanese women, and a report from Central China found that the rates of HPV-16 and/or -18 infections in patients with 73 lung tumors were significantly higher than in 34 non-cancer control subjects (27.7 vs. $5.9 \%$ ) (19). Also they found that $44.1 \%$ of (138/313) NSCLC samples were positive, while $4.2 \%$ (4/96) of lung benign controls were positive (20). Our data showed that the high risk HPV genotypes $16 / 18$ were $43.1 \%$ and $5.6 \%$ in lung squamous cell carcinoma cases and non-cancer control cases, respectively $(\mathrm{P}<0.001)$. It is very similar to the study from the central part of China in NSCLC (20), but our study focused on lung squamous cell carcinomas cases.

In the majority of carcinomas associated with high-risk HPV and some advanced HPV-associated precancerous lesions, the whole viral genome or its fragment is integrated into the chromosomal DNA of the host cell whereas the HPV genome was retained as episomal molecules in early dysplastic low-grade lesions (17). Although the mechanism involved in switching from episomal state to viral integration was yet unclear, it was suspected that methylation pattern on HPV genome was different in episomal and integrated states. Kim et al reported that the overall methylation status of the LCR was greater than that seen in the more highly differentiated cells (30).
Since HPV integration may result in deletion of the $E_{2}$ gene, the status of HPV in the host cells was determined on the basis of the $E_{2} / E_{6}$ ratio (24). When the ratio was equal to or higher than 1, all the HPV genome was considered to be in an episomal form and not integrated. The lack of amplified $\mathrm{HPV} \mathrm{E}_{2}$ genome was considered to indicate the integration of all the HPV genome into the host genome. When the $E_{2} / E_{6}$ ratio was larger than zero and smaller than 1 , the condition was considered as the mixture of episomal and integrated forms, where a portion of HPV genome was integrated into the host genome. In our study, real-time PCR was used in 27 samples to confirm the presence of HPV-16. $\mathrm{E}_{2}$ was not found in $59.3 \%(16 / 27)$ of the samples, suggesting that at least a partial HPV-16 genome was integrated into the host genome, which is similar to the $66.7 \%$ reported in Chile (31)

Although the viral load was low in our study, ranging from 0.003 to 44.942 copies per nanogram of genomic DNA, which corresponds to $<1$ to 2 copies/cell, our data were very similar to the reports from a Chinese study on esophageal cancer tissues ( $<1$ to 157 copies/cell) (32) and a Finnish study on head and neck SCC (4.6 to 49 copies/cell) (33). The low viral load may be sufficient to promote carcinogenesis especially if viral DNA is integrated into the cell (34). Our data emphasize the importance of high-risk HPV DNA integration into the host genome contributing to lung squamous cell carcinogenesis. 
In summary, there is a significant difference of HPVpositivity between lung squamous cell carcinomas and noncancer controls, and the HPV-16 positive had higher risk than HPV-16 negative in the development of lung squamous cell carcinomas. A possible mechanism is the integration of HPV-16 into the host genome.

\section{Acknowledgements}

We thank Dr Suminori Akiba, Kagoshima University, Japan, for proving assistance in analyzing the data. We also thank Dr Zhang Guanjun for his contribution in the pathological diagnosis, and assistance in the preparation of paraffinembedded slices.

\section{References}

1. Bosch FX, Lorincz A, Munoz N, Meijer C and Shah KV: The causal relationship between human paillomavirus and cervical cancer. J Clin Pathol 55: 244-265, 2002.

2. Yanagawa N, Osakabe M, Hayashi M, Tamura G and Motoyama T: Detection of HPV-DNA, p53 alterations, and methylation in penile squamous cell carcinoma in Japanese men. Pathol Int 58: 477-482, 2008.

3. Clavel CE, Nawrocki B and Bosseaux B: Detection of human papillomavirus DNA in bronchopulmonary carcinomas by hybrid capture II: a study of 185 tumors. Cancer 88: 1347$1352,2000$.

4. Chiou HL, Wu MF and Liaw YC: The presence of human papillomavirus type 16/18 DNA in blood circulation may act as a risk marker of lung cancer in Taiwan. Cancer 97: 1558-1563, 2003 .

5. Snijders P, van den Brule A, Meijer C and Walboomers J: HPV and cancer of the aerodigestive tract. Papillomavirus Rep 6: 157-162, 1995

6. Nadji S, Mokhtari-Azad T, Mahmoodi M, Yahyapour Y, Naghshvar F, Torabizadeh J, Ziaee A and Nategh R: Relationship between lung cancer and human papillomavirus in north of Iran, Mazandaran province. Cancer Lett 248: 41-46, 2007.

7. Wen Cheng Y and Lee H: Environmental exposure and lung cancer among nonsmokers: an example of Taiwanese female lung cancer. J Environ Sci Health C Environ Carcinog Ecotoxicol Rev 21: 1-28, 2003

8. Syrjanen KJ: Condylomatous changes in neoplastic bronchial epithelium. Report of a case. Respiration 38: 229-304, 1979.

9. Syrjanen KJ: Epithelial lesions suggestive of a condylomatous origin found closely associated with invasive bronchial squamous cell carcinoma. Respiration 49: 150-160, 1980.

10. Hirayasu T, Twamasa T and Kamada Y: Human papillomavirus DNA in squamous cell carcinoma of the lung. J Clin Pathol 49: 810-817, 1996.

11. Syrjanen KJ: HPV infections and lung cancer. J Clin Pathol 55: 885-891, 2002

12. Miyagi J, Tsuhako K, Kinjo T, Iwamawa T and Hirayasu T: Recent striking changes in histological differentiation and rate of human papillomavirus infection in squamous cell carcinoma of the lung cancer in Okinawa: a subtropical island in Southern Japan. J Clin Pathol 53: 676-684, 2000.

13. Cheng YW, Chiou HL, Sheu GT, Hsieh LL, Chen JT, Chen CY, $\mathrm{Su} \mathrm{JM}$ and Lee $\mathrm{H}$ : The association of human papillomavirus 16/18 infection with lung cancer among nonsmoking Taiwanese women. Cancer Res 61: 2799-2803, 2001

14. Cheng YW, Lee H, Shiau MY, Wu TC, Huang TT and Chang YH: Human papillomavirus type 16/18 up-regulates the expression of interleukin-6 and antiapoptotic Mcl-1 in nonsmall cell lung cancer. Clin Cancer Res 14: 4705-4712, 2008.

15. Cheng YW, Wu MF, Wang J, Yeh KT, Goan YG, Chiou HL, Chen CY and LH: Human papillomavirus 16/18 E6 oncoprotein is expressed in lung cancer and related with p53 inactivation. Cancer Res 67: 10686-10693, 2007.
16. Aguayo F, Meneses M, Corvalan A, Munoz M, Koriyama C, Eizuru Y and Akiba S: Identification of human papillomavirus 16 (HPV 16) in keratinizing lung carcinoma. Rev Chil Enferm Respire 18: 83-89, 2002.

17. Castillo A, Aguayo F, Koriyama C, Shuyama K and Akiba S: Human papillomavirus in lung carcinomas among three Latin American countries. Cancer Sci 15: 883-888, 2006.

18. Park MS, Chang YS and Shin JH: The prevalence of human papillomavirus infection in Korean non-small cell lung cancer patients. Yonsei Med J 48: 69-77, 2007.

19. Fei Y, Yang J, Hsieh WC, Wu JY, Wu TC, Goan YG, Lee H and Cheng YW: Different human papillomavirus 16/18 infection in Chinese non-small cell lung cancer patients living in Wuhan, China. Jpn J Clin Oncol 36: 274-279, 2006.

20. Wang YP, Wang AF, Jiang R, Pan HX, Huang BX, Lu Y and Wu CH: Human papillomavirus type 16 and 18 infection is associated with lung cancer patients from the central part of China. Oncol Rep 20: 333-339, 2008.

21. Greer CE, Wheeler CM and Manos MM: PCR amplification from paraffin-embedded tissues: sample preparation and the effects of fixation. In PCR Primer: a laboratory manual. Carl WD and Gabriela SD (eds). Cold Spring Harbor Laboratory Press, New York, pp99-112, 1995.

22. Gillison ML and Shah KV: Role of mucosal human papillomavirus in non-genital cancers. J Natl Cancer Inst Monogr 31: 57-65, 2003.

23. Ketler B, van Doorn LJ, Schrauwen L, Molijin A, Sastrowijoto S, ter Schegget J, Lindeman J, ter Harmsel B, Burger $M$ and Quint W: Development and clinical evaluation of a highly sensitive PCR-reverse hybridization line probe assay for detection and identification of anogenital human papillomavirus. J Clin Microbiol 137: 2508-2517, 1999.

24. Peitsaro P, Johansson B and Syrjanen S: Integrated human papillomavirus type 16 is frequently found in cervical cancer precursors as demonstrated by a novel quantitative real-time PCR technique. J Clin Microbiol140: 886-891, 2002.

25. Lele SM, Pou AM and Ventura K: Molecular events in the progression of recurrent respiratory papillomatosis to carcinoma. Arch Pathol Lab Med 126: 1184-1188, 2002.

26. Zafer E, Ergun MA and Alver G: Detection and typing of human papillomavirus in non-small cell lung cancer. Respiration 71: 88-90, 2004.

27. Steckley SL, Pickworth WB and Haverkos HW: Cigarette smoking and cervical cancer. Part II: a geographic variability study. Biomed Pharmacother 57: 78-83, 2003.

28. Noutsou A, Koffa M, Ergazaki M, Siafakas NM and Spandidos DA: Detection of human papillomavirus (HPV) and K-ras mutations in human lung carcinomas. Int J Oncol 8: 1089-1093, 1996.

29. Hsu NY, Cheng YW, Lin MH and Chou MC: Association of expression of human papillomavirus 16/18 E6 oncoprotein and survival for pathological stage I non-small cell lung cancer. Proc Am Assoc Cancer Res 49: 1124, 2008.

30. Kim K, Garner-Hamrick PA, Fisher C, Lee D and Lambert PF: Methylation pattern of papillomavirus DNA its influence on E2 function, and implication in viral infection. J Virol 77: 12350-12459, 2003.

31. Aguayo F, Castillo A, Koriyama C, Higashi M, Itoh T, Capetillo M, Shuyama K, Corvalan A, Eizuru Y and Akiba S: Human papillomavirus-16 is integrated in lung carcinomas: a study in Chile. Cancer Res UK 97: 85-91, 2007.

32. Si HX, Tsao SW, Poon CS, Wang LD, Wong YC and Cheung AL: Viral load of HPV in esophageal squamous cell carcinoma. Int $\mathrm{J}$ Cancer 103: 496-500, 2003.

33. Koskinen W, Chen RW, Leivo I, Makitie A, Back L, Kontio R, Suuronen R, Lindqvist C, Auvinen E, Molijn A, Quint WG, Vaheri A and Aaltonen LM: Prevalence and physical status of human papillomavirus in squamous cell carcinomas of the head and neck. Int J Cancer 107: 401-406, 2003.

34. Si HX, Tsao SW, Poon CS, Wong YC and Cheung AL: Physical status of HPV-16 in esophageal squamous cell carcinoma. J Clin Virol 32: 19-23, 2005. 